\title{
The perception amongst a population of high school students in South Africa about ocular mani- festations of HIV/AIDS*
}

\section{IT Melwa a and OA Oduntan ${ }^{b}$}

a Department of Optometry, School of Health Care Sciences, University of Limpopo (Turfloop Campus), P. Bag x1106, Sovenga, 0727 South Africa

bDiscipline of Optometry, Faculty of Health Sciences, University of KwaZulu-Natal, Private Bag x54001, Durban, 4000 South Africa

<oduntanoa@ukzn.ac.za>

<irene.melwa@ul.ac.za>

Received 29 November 2011; revised version accepted 30 August 2012

\begin{abstract}
HIV and AIDS can result in visual impairment, therefore it is important that those who have or at risk of contracting the disease have a basic knowledge of its ocular manifestations, so that they may seek eye care early. This study assessed the perceptions of a sample of senior high school students atthe Capricorn district, Limpopo Province, South Africa about the ocular manifestations of HIV/ AIDS and its management. Questionnaires were distributed to the students in their classrooms after school hours and upon completion were collected the same day. Data analysis revealed that $27.8 \%$ of the participants agreed that HIV/AIDS can affect the eyes. Another $27.8 \%$ responded that HIV/AIDS could cause dry eyes. Less than a third
\end{abstract}

(31.4\%) indicated that the disease could cause red eyes, $31.5 \%$ and $38.1 \%$ respectively indicated that HIV/AIDS could cause cancer of the eyelids and the eyeball. About half of the respondents (52\%) agreed that the disease could cause swollen eyelids; while about $46 \%$ agreed that vision loss or blindness could occur in HIV/AIDS. Many $(65.6 \%)$ indicated that an ophthalmologist or an optometrist should be consulted for HIV/AIDS-related eye problems and only $16.5 \%$ reported that traditional healers could be consulted. Perception about the ocular manifestations of HIV and AIDS is poor among the participants, suggesting a need for awareness campaigns and education. (S Afr Optom 2012 71(3) 117-122)

Key words: HIV, AIDS, ocular manifestations of HIV/AIDS.

\section{Introduction}

Sub-Saharan Africa has just over $10 \%$ of the world's population, yet is home to more than $60 \%$ of all people living with HIV ${ }^{1}$. South Africa has a high prevalence of HIV and AIDS and for example, a prevalence of $10.6 \%$ was reported in a peri-urban community population ${ }^{2}$. In 2008, an estimated 5.7 million South Africans were living with HIV/AIDS ${ }^{3}$. As a consequence of HIV infection and AIDS,

aBOptom MOptom

bBSc (Hons)Optom PhD

*This paper forms part of research for the degree Master in Optometry (M Optom) at the University of Limpopo, undertaken by Irene Melwa with the supervision of Professor Oduntan. 
opportunistic organisms may gain access into the body including the eyes, causing various diseases. Visual impairment is a public health problem and constitutes an important socioeconomic burden on Sub-Saharan Africa ${ }^{4}$. HIV/AIDS-related eye infections may therefore compound the already high prevalence of visual impairment in the region. Ocular or orbital diseases may be the first manifestations of HIV/AIDS and can be an indicator of previously undiagnosed HIV infection ${ }^{5}$. Therefore, early diagnosis and proper treatment is required to avert unnecessary blindness among HIV/AIDS patients. It is therefore important that those who have the disease or who are at risk of contracting it be aware of both the systemic and ocular implications of the condition.

Ocular complications that occur in about $75-80 \%$ of AIDS patients include non-infectious conditions such as retinal microangiography, opportunistic infections, tumours and neuro-ophthalmological lesions ${ }^{6,7}$. Immune recovery uveitis (a non-infectious inflammation) has also been associated with HIV/ AIDS ${ }^{8}$. Opportunistic viral infections such as those of cytomegalovirus (CMV), herpes simplex (HSV), varicella zoster (VZV) and bacterial infections such as those of toxoplasma gondii, mycobacterium and various fungal pathogens have been associated with HIV/AIDS 7, 9. Cytomegalovirus retinitis results in blurred vision, visual field loss, light flashes or floaters ${ }^{10}$. Other common opportunistic infections that may affect the eyes include ocular syphilis, tuberculosis (TB) and toxoplasmosis, 5, 11, 12. Early diagnosis and prompt treatment may be sight-saving in patients with such conditions ${ }^{12}$.

AIDS may cause neoplasms such as Kaposi's sarcoma (which may affect the eyelids and the conjunctiva) and lymphomas ${ }^{13}$. Also ocular surface squamous neoplasia (OSSN) may manifest in AIDS patients $^{14-16}$. Herpes zoster ophthalmicus (HZO) is common among those with the condition ${ }^{17}$ and may occur in individuals who appear healthy but are actually infected with HIV ${ }^{18}$. Disorders of HZO include retinal vasculitis, herpetic retinopathy, optic neuritis and oculomotor palsies ${ }^{19}$. Vesicular lesions of the eyelid, blepharitis and loss of eyelashes as well as trichiasis and cicatrical entropion may also occur in patients with $\mathrm{HZO}^{20}$. HIV may cause optic atrophy and diplopia, the latter due to palsies of cranial nerves III, IV, and VI ${ }^{21}$. With such serious ocular manifestations of HIV/AIDS, it is important for those living with the condition and those who are at risk of contracting the disease to have basic knowledge of its ocular manifestations. Those affected should also be aware of who to consult for diagnosis and management.

In 2008, young people worldwide accounted for $45 \%$ of new HIV infections ${ }^{3}$, the situation may not be different in South Africa. The country has an elaborate national policy on HIV and AIDS for preprimary, primary and secondary school students as well as their teachers 22 and inclusion of HIV/AIDS education in the school curricula is part of this policy. The curricula include provision of information on HIV/AIDS, HIV transmission, development of skills necessary for the prevention of HIV transmission as well as management and non-discrimination towards persons with the condition $^{22}$. However, ocular manifestations of the condition were not specifically indicated in the document. The purpose of this study therefore was to evaluate the perception of the high school students about the ocular manifestations of HIV/AIDS.

\section{Methodology}

Ethical approval to conduct this study was granted by the University of Limpopo Research and Ethics Committee (MREC/H/42/2008:PG). Permission to conduct the study was also granted by the Department of Education and the 18 principals of schools in which the study was conducted. A document obtained from the provincial Department of education indicated that there were 371 high schools in the Capricorn district and there were 25, 1196 students. Cluster sampling was used to select the 18 high schools included in the study and 3,070 students were systematically selected for the study from the class registers of senior grades (10 to 12). The selected students and their parents or guardians signed the informed consent forms to participate in the study. A questionnaire on demography, basic ocular manifestations of HIV and AIDS, who to consult in case of suspected ocular signs and symptoms of the conditions et cetera were administered to the students over a period of one month. The questionnaires were distributed to the students in their classrooms after school hours and the questions were read to, and clarified with the participants before completion. They were assured of confidentiality and anonymity. The questionnaires were collected the same day upon completion by 
the students. Data was analyzed using the Statistical Packages for Social Sciences (SPSS) computer program version 16 .

\section{Results}

Two thousand six hundred and fifty nine (2659) of the 3070 selected students completed the questionnaire at the 18 schools; a response rate of $86.6 \%$. Contributory factors for not having greater response rate included absence of some female students during this period due to pregnancy or maternity reasons and some males students went for circumcision. The sample included (46.4\%) males and (53.1\%) females, others $(0.5 \%)$ did not indicate their gender. Their ages ranged from 14 to 28 years (Mean 17.82 $\pm 1.77)$. Less than a third of the respondents $(27.8 \%)$ agreed that HIV/AIDS could affect the eyes while $42.8 \%, 26.7 \%$ and $2.7 \%$ respectively disagreed, did not know the answer and did not respond to the question. However, most $(65.6 \%)$ of the respondents agreed that an ophthalmologist or optometrist should be consulted for eye symptoms that are HIV/AIDS-related. Only a few respondents $(16.5 \%)$ agreed that a traditional healer should be consulted for eye symptoms that were HIV/ AIDS-related. The responses to the other questions are shown in the table below. Gender did not influence the responses $(p>0.05)$.

Table 1: Listed questions and the responses of the participants.

\begin{tabular}{|c|c|c|c|c|}
\hline \multirow[b]{2}{*}{ Questions } & \multicolumn{4}{|c|}{ Response (\%) } \\
\hline & Yes & No & $\begin{array}{l}\text { I don't } \\
\text { know }\end{array}$ & $\begin{array}{l}\text { No } \\
\text { response }\end{array}$ \\
\hline Can HIV/AIDS decrease the risk of eye infections? & 40.3 & 26.6 & 31.0 & 2.1 \\
\hline Can HIV/AIDS cause red eyes? & 31.4 & 31.3 & 35.2 & 2.0 \\
\hline Can HIV/AIDS cause cancer of the eyelids? & 31.5 & 26.0 & 40.8 & 1.7 \\
\hline Can HIV/AIDS cause dry eyes? & 27.8 & 31.0 & 39.2 & 2.0 \\
\hline $\begin{array}{l}\text { Can HIV/AIDS infection affect the transparent front of the eye } \\
\text { (cornea)? }\end{array}$ & 26.2 & 25.1 & 46.8 & 1.9 \\
\hline Can cancer developing on the eyeball be due to HIV/AIDS? & 38.1 & 22.7 & 37.3 & 1.9 \\
\hline $\begin{array}{l}\text { Can HIV/AIDS infections cause swollen eyelids and discharge } \\
\text { from the eyes? }\end{array}$ & 52.0 & 15.9 & 30 & 2.1 \\
\hline $\begin{array}{l}\text { Can HIV/AIDS cause persistent gritty (sandy) sensation in the } \\
\text { eye? }\end{array}$ & 19.9 & 26.4 & 51.5 & 2.2 \\
\hline $\begin{array}{l}\text { Can HIV/AIDS cause itching and burning sensations in the } \\
\text { eye? }\end{array}$ & 26.0 & 28.2 & 43.7 & 2.1 \\
\hline Can HIV/AIDS cause vision loss (blindness) & 46.0 & 28.1 & 24.2 & 1.7 \\
\hline Can HIV/AIDS related infections cause painful eyes? & 42.9 & 23.2 & 32.1 & 1.8 \\
\hline
\end{tabular}




\section{Discussion}

According to the United Nations AIDS (UNAIDS) programme on HIV/AIDS and World Health Organization (WHO) report (2008), worldwide young people account for $45 \%$ of new HIV infections ${ }^{3}$, presumably because they are more sexually active and are more likely to take risks such as unprotected sexual activity; hence young people were targeted in this study. Also, ocular manifestations of the disease are not specifically mentioned in the schools' curricula on HIV/AIDS. In view of the high prevalence of HIV/AIDS in the country, the adverse effects of the condition on the eye and non-inclusion of the ocular manifestation of the disease in the educational policy; it was considered of interest to evaluate the awareness and perception of the ocular involvement of HIV/ AIDS among high school students

Although, knowledge, awareness, and attitudes towards HIV and AIDS among adolescents and high school students have been reported in many parts of the world including South Africa $23-26$ and ocular manifestations of the condition have been reported in many developing nations including those in Africa27-30, no documented study could be found on ocular manifestations in South Africa. In the endemic areas, such as South Africa, young people may have an idea of ocular manifestations of HIV and AIDS in view of their interaction with people living with the conditions. However, this knowledge may be limited, therefore, there is a need for awareness and educational campaigns against HIV and AIDS that include ocular manifestations of the disease. Although detailed knowledge of ocular complications of the disease is not necessary, it is essential for those infected and those who are at risk of being infected with the disease to know that HIV/AIDS can affect the eyes or cause visual impairment and that early eye examination is important to avert visual impairment.

Limitations of this study include its study design being quantitative study and such studies have their inherent limitations 31 , which may manifest in this study. Such limitations include small population sample which may decrease the possibility of generalization 32 . This may not be the case with this study as a large sample was used. However, another limitation of this type of study is that some participants may respond in a specific manner simply because of awareness of being observed 33 (cited by Walker ${ }^{31}$ ).
This may in a way be the case in this study. In spite of these and other limitations, however, quantitative studies have key roles to play in the development of new knowledge, generating questions and hypotheses that could form the basis for further research 31 . This study is therefore of significance in highlighting the poor awareness of high school students about ocular aspects of HIV/AIDS. Findings could form the basis for further and larger research studies on similar topics, which is critical in the prevention of blindness due to HIV/AIDS.

Less than a third of the respondents in this study understood that HIV/AIDS could affect the eyes. This result is of concern in view of the several HIV/ AIDS-related conditions that can affect the eyes 5,34 and lead to visual impairment and blindness. HIV/ AIDS infections itself is a devastating health problems, and it may be unbearable if accompanied by visual impairment and blindness. Therefore, possible ocular manifestation should be prevented among those living with the condition. It is however, a good finding that many of the respondents $(65.6 \%)$ knew who should be consulted for eye symptoms that are related to HIV/ AIDS. Only $16.5 \%$ wrongly indicated that traditional healers should be consulted. These findings are obviously not unexpected as many of the respondents were from the rural areas and are known to patronize the traditional healers for many of their ailments 35 .

This suggests that many of the students knew that the medical intervention is needed for HIV/AIDS-related diseases. A patient who has AIDS may complain of red eye, which may be due to iridocyclitis 21 . HIVinfected and AIDS patients may also complain of a chronic, mildly irritated red eye that is resistant to treatment (allergic conjunctivitis), while others may complain of tearing, photophobia, foreign body sensation, dry eye (keratoconjunctivitis sicca) and redness 36 . These may be early signs of ocular involvement; therefore eye care should be sought. However, only a smaller proportion $(31.4 \%)$ of the respondents in this study agreed that HIV and AIDSrelated infections can cause red eyes and fewer agreed that HIV/AIDS-related infections can cause dry eye. Further, only $26.0 \%$ agreed that HIV/AIDS can cause itching and burning sensations in the eye (Table 1). These suggest that, if many of these respondents have red eyes, dry eyes, itching or burning sensation that are HIV/AIDS-related, they might not relate such signs to HIV and AIDS. This may cause a delay in 
seeking eye examination and may result in possible visual impairment.

Although tumours such as Kaposi's sarcoma, conjunctival squamous cell dysplasia and neoplasia are associated with HIV/AIDS infection7, 10, 13-16, only a small proportion $(38.1 \%)$ of the participants in this study agreed that tumours can develop on the eye ball due to HIV/AIDS-related diseases. Also, fewer $(31.5 \%)$ agreed that HIV/AIDS-related infections can cause cancer of the eyelids (Table 1). Many of the eye involvements such as non-Hodgkin's lymphomas can predispose the infected individuals to cortical visual $\operatorname{loss}^{37}$; however, less than half $(46.0 \%)$ of the respondents in the present study agreed that HIV/ AIDS can cause visual impairment. Above-mentioned tumours if not diagnosed and treated earlier could result in enucleation (removal of the eyeball) or exenteration (removal of the eyeball and orbital contents due to intraocular and orbital extension of the recurrent tumours $)^{38}$.

Although herpes zoster ophthalmicus due to HIV and AIDS may cause severe pain 39 , less than half $(42.9 \%)$ of the respondents agreed that HIV/AIDSrelated infections could cause painful eyes. Responses to other questions such as whether AIDS can affect the cornea, possible gritty sensation, itching and burning sensation in the eye were also poor (Table 1). No gender differences in responses to the questions were observed in this study $(p>0.05)$ and this was consistent with other survey studies among youths on HIV and AIDS40, 41.

The poor responses to questions on ocular manifestations of HIV and AIDS in this study contrasts sharply with the responses to questions on knowledge about HIV and AIDS in the same sample population ${ }^{42}$, suggesting the need for an appropriate awareness campaign about HIV/AIDS and the eyes among South African adolescents and youths. Significant improvement in the knowledge of HIV/ AIDS following education programmes for students have been reported 43 . It is therefore, recommended that information on ocular manifestations of HIV/ AIDS and who to consult for eye-related aspects of the diseases should be included in AIDS awareness or health promotion campaigns. Such intervention could be in the form of media education programmes and inclusion in school curricular.

\section{References}

1. United Nations AIDS programme on HIV/AIDS (UNAIDS) and World Health Organization. Global summary of prevalence of AIDS epidemic. Special report on HIV prevention. Geneva, Switzerland, WHO 2005.

2. Jaspan HB, Berwick JR, Myer L, Mathews C, Flisher AJ, Wood R, Bekker, L-G. Adolescent HIV prevalence, sexual risk and willingness to participate in HIV vaccine trials. $J$ Adolesc Health 200639 642-648.

3. United Nations AIDS programme on HIV/AIDS (UNAIDS) and World Health Organization. Eight-year trend shows new HIV infections down by $17.0 \%$ - most progress seen in sub-Saharan Africa. Geneva: Joint United Nations Programme on HIV/AIDS 9th press release. Geneva, Switzerland, WHO 2009.

4. Omgbwa EA, Boitte JP, Traoré J. Ocular disorders causing blindness in working-age outpatient: a prospective study at the African Institute of Tropical Ophthalmology, (IOTA, Bamako, Mali). Sante 200515 241-245.

5. Kunkel J, Schürmann D, Pleyer U, Rüther K, Kneifel C, Krause L, Reichert M, Ignatius R, Schneider T. Ocular syphilis-indication of the previously unknown HIV-infection. J Infect 200958 32-36.

6. Meyer D. Eye signs that alert the clinician to a diagnosis of AIDS. S Afr J Dent 200560 386-387.

7. Ah-Fat FG, Batterbury M. Ophthalmic complications of HIV/AIDS. Postgrad Med J 199672 725-730.

8. Gharai S, Ventatesh P, Garg S, Sharma SK, Vohra R. Ophthalmic manifestations of HIV Infections in India in the era of HAART: Analysis of 100 consecutive patients evaluated at a tertiary eye care center in India. Ophthal Epidemiol 200815 261-271.

9. Morales HV. Ocular manifestations of HIV/AIDS. Curr Opin Ophthalmol 200213 397-403.

10. Bhatia RS. Ophthalmic manifestations of AIDS. J Indian Acad Clin Med 20023 85-88.

11. Banker AS. Posterior segment manifestations of Human immune deficiency syndrome. Indian J Ophthalmol 2008 56 377-383.

12. Alvarez GG, Roth VR, Hodge W. Ocular tuberculosis: diagnostic and treatment challenges. Intern J Infect Dis 2009 13 432-435.

13. Curtis TH, Durairaj VD. Conjunctival Kaposi's sarcoma as the initial presentation of human immunodeficiency virus infection. Ophthal Plastic Reconstr Surg 200521 14-315.

14. Beare NAV, Batumba NH. The impact of HIV on Sub-Saharan African eye departments. Eye 200612 1414-1415.

15. Chisi SK, Kollmann MK, Karimurio J. Conjunctival squamous cell carcinoma in patients with human immunodeficiency virus infection seen at two hospitals in Kenya. East Afr Med J 200683 267-270.

16. Kiire CA, Dhillon B. The etiology and association of conjunctival intraepithelial neoplasia. Brit J Ophthalmol 2006 90 109-113.

17. Franco-Paredes C, Bellehemeur T, Merchant A, Sanghi P, DiazGranados C and Rimland D. Aseptic meningitis and 
optic neuritis preceding varicella-zoster progressive outer retinal necrosis in a patient with AIDS. AIDS 2002161045 1049.

18. Owoeye JF, Ademola-Popoola DS. Herpes zoster infecton and HIV seropositivity among eye patients. University of llorin Teaching Hospital experience. West Afr J Med 2003 22 136-138.

19. Jeng HB, Holland GN, Lowder CY, Deegan III WF, Raizman MB, Meisier DM. Anterior segment and external ocular disorders associated with human immunodeficiency virus disease. Surv Ophthalmol 200752 329-368.

20. Wiafe B. Herpes zoster ophthalmicus in HIV/AIDS. Comm Eye Health 200316 35-36.

21. Lima BR. Ophthalmic manifestations of HIV infection. Digit J Ophthalmol 20041.

22. South African Department of Education. Revised national curriculum statement, grades R-9 (Schools). Gov Gazette No. 443 23406, 2002.

23. Singh SK, Manandhar N, Prasai M, Patowary S, Krishna G. An awareness study of HIV/AIDS among adolescent students of Chitwan District, Nepal. J Inst Med 200527 17-20.

24. Dadkha B, Mohammadi MA, Mozafari N. Knowledge and attitude towards HIV/AIDS among college students in Ardabil, Iran. Res J Biol Sci 20083 28-31.

25. Oyo-Ita AE, Ikpeme BM, Etokidem AJ, Offor JB, Okokon EO, Etuk SJ. Knowledge of HIV/AIDS among secondary school adolescents in Calabar, Nigeria. Ann Afr Med 2005 4 2-6.

26. Anderson KG, Beutel AM. HIV/AIDS prevention knowledge among youth in Cape Town, South Africa. J Soc Sci 20073 143-151.

27. Moraes HV. Ocular manifestation of HIV/AIDS. Curr Opin Ophthalmol 200213 397-403.

28. Shah SU, Kerkar SP, Pazera AR. Evaluating ocular manifestation and blindness in HIV/AIDS patients on HAART in a tertiary care hospital in western India. Brit $J$ Ophthalmol 200993 88-90.

29. Ayena KD, Amedome KM, Agbo AR, Pketessou-Ayivon AL, Dzidzinyo KB, Djagnikpo PA, Banla M, Balo KP. Ocular Manifestations in HIV/AIDS patients undergoing highly active antiretroviral treatment (HAART) in Togo. Med Trop 201070 137-140.

30. Assefa Y, Yohannes AG, Melese A. Ocular manifestations of HIV/AIDS patients in Gonda University Hospital, North West Ethiopia. Ethiop J Health Dev 200620 166-169.

31. Walker W. The strengths and weaknesses of research designs involving quantitative measures. J Res Nurs $2005 \mathbf{1 0}$ 571-582.

32. Carr LT. The strengths and weaknesses of qualitative and quantitative research: what method for nursing. $J A d v$ Nurs 199429 716-721.

33. Haughey BP. (1994a) Evaluating quantitative research design: Part 2. Crit Care Nurs December 169-172.

34. Babu RB, Sudharshan S, Kumarasamy N, Therese L, Biswas J. Ocular tuberculosis in acquired immunodeficiency syndrome. Am J Ophthalmol 200642 413-418.

35. Peltzer K. Perceived treatment efficacy of the last experienced illness episode in a community sample in the North- ern Province, South Africa. Curationis 200023 57-60.

36. Chronister CL. Review of external ocular diseases associated with AIDS and HIV infection. Optom Vis Sci 1996 73 225-230.

37. Vrabec TR. Posterior segment manifestations of HIV/ AIDS. Surv Ophthalmol 200449 131-157.

38. Semo B, Bison G, Nkomazana O. Immune status of HIVpositive patients with ocular surface squamous neoplasia in Botswana [abstract 27]. Presented at the 8th international conference on malignancies in HIV and other immunodeficiency. Bethesda, MD; April 29-30, 2004.

39. Cunningham ET and Margolis TP. Ocular manifestations of HIV infection. N Engl J Med 1998339 236-244.

40. Peltzer K, Promtussananon S. HIV/AIDS knowledge and sexual behavior among junior secondary school students in South Africa. J Soc Sci 2005 1 1-8.

41. Kyrychenko P, Kohler C, Sathiakumar N. Evaluation of a school-based HIV/AIDS educational intervention in Ukraine. J Adoles Health 200636 900-907.

42. Melwa IT, Oduntan OA. Knowledge about HIV and AIDS among young South Africans in the Capricorn District, Limpopo Province. Health Edu J 201171 189-194.

43. Mahat G, Scoloveno MA, De-Leon TD, Frenkel J. Preliminary evidence of an adolescent HIV/AIDS: Peer education program. J Ped Nurs 200823 358-363. 